Nondestructive Evaluation of the Oxidation and Strength of the Fort Saint Vrain HTGR Support Block
G. L. Tíngey
J. M. Prince
G. J. Posakony
R. W. Hill
W. C. Morgan
D. L. Lessor

April 1982

Prepared for the U.S. Department of Energy under Contract DE-AC06-76RLO 1830

Pacific Northwest Laboratory Operated for the U.S. Department of Energy by Battelle Memorial Institute 


\section{DISCLAIMER}

This report was prepared as an account of work sponsored by an agency of the United States Government. Neither the United States Government nor any agency Thereof, nor any of their employees, makes any warranty, express or implied, or assumes any legal liability or responsibility for the accuracy, completeness, or usefulness of any information, apparatus, product, or process disclosed, or represents that its use would not infringe privately owned rights. Reference herein to any specific commercial product, process, or service by trade name, trademark, manufacturer, or otherwise does not necessarily constitute or imply its endorsement, recommendation, or favoring by the United States Government or any agency thereof. The views and opinions of authors expressed herein do not necessarily state or reflect those of the United States Government or any agency thereof. 


\section{DISCLAIMER}

Portions of this document may be illegible in electronic image products. Images are produced from the best available original document. 


$$
\begin{aligned}
& \text { PNL }-4203 \\
& \text { DE82 }
\end{aligned}
$$

NONDESTRUCTIVE EVALUATION OF THE OXIDATION AND STRENGTH OF THE FORT SAINT VRAIN HTGR SUPPORT BLOCK

G. L. Tingey, G. J. Posakony, W. C. Morgan, J. M. Prince, R. W. Hill, and D. L. Lessor

April 1982

Prepared for the U.S. Department of Energy under Contract DE-ACO6-76RLO 1830

Pacific Northwest Laboratory Richland, Washington 99352 
CONTENTS

\begin{tabular}{|c|c|c|c|c|c|c|c|c|c|c|}
\hline INTRODUCTION & - & - & • & • & • & • & • & • & - & \\
\hline NONDESTRUCTIVE E & EVALUATION & • & • & • & $\bullet$ & $\cdot$ & • & • & • & 0 \\
\hline \multicolumn{3}{|c|}{ Sonic Velocity Measurements } & $\cdot$ & $\bullet$ & • & $\cdot$ & • & • & - & \\
\hline \multicolumn{3}{|c|}{ Eddy Current Measurements } & $\cdot$ & $\cdot$ & $\cdot$ & $\cdot$ & • & • & - & \\
\hline Ultrasonic & Backscatter & • & - & • & • & • & • & - & - & \\
\hline \multicolumn{6}{|c|}{ Examination of Fort Saint Vrain Support Block } & $\cdot$ & - & • & - & 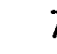 \\
\hline CONCLUSIONS AND & RECOMMENDATI & JNS & • & • & - & • & - & - & - & 10 \\
\hline REFERENCES & • & - & • & • & - & - & - & - & • & 1] \\
\hline ACKNOWLEDGMENT & • & • & • & • & • & • & • & - & - & 12 \\
\hline
\end{tabular}




\title{
NONDESTRUCTIVE EVALUATION OF THE OXIDATION AND STRENGTH \\ OF THE FORT SAINT VRAIN HTGR SUPPORT BLOCK
}

\author{
G. L. Tingey, G. J. Posakony, W. C. Morgan, \\ J. M. Prince, R. W. Hill, and D. L. Lessor \\ Pacific Northwest Laboratory \\ Richland, Washington
}

\section{INTRODUCTION}

The Fort Saint Vrain nuclear power reactor is a helium cooled, graphite moderated reactor designed to produce $330 \mathrm{MW}$ of electrical power with a helium outlet temperature approaching $800^{\circ} \mathrm{C}$. Because of the high temperatures involved in operation of this reactor, the entire core is constructed of ceramic materials. Thus, the $\mathrm{UO}_{2} / \mathrm{ThO}_{2}$ nuclear fuel is contained in nuclear grade, graphite hexagonal blocks which also act as the ducting for the inert helium coolant. Considerable attention was given to the reaction of the hot graphite core with oxidizing impurities and operating limits were placed on reactor operation to prevent excessive oxidation from occurring.

The core of the reactor rests on graphite blocks which are supported by an array of six-inch diameter graphite posts. Since the support structure is out of the central core and will not significantly affect the nuclear reactivity, the need for high purity nuclear graphite is lessened and the Fort Saint Vrain reactor used unpurified graphite for both the support blocks (PGX) and the support posts (ATJ). One of the consequences of the higher impurity levels of PGX graphite, however, is a significantly higher reactivity to the oxidizing coolant impurities. Because of this, greater attention has been given to the evaluation of the high-temperature oxidation of the support structure and the resultant potential loss of strength.

Several methods may be used to evaluate the potential loss of strength of the support structure. These include: (1) determination of reaction rates of the specific graphite types in laboratory studies and applying these rates to 
reactor conditions, (2) monitoring the coolant impurity levels to determine the effect of oxidation of the graphite, (3) placing graphite surveillance monitors in the vicinity of the support structure and withdrawing and analyzing them periodically as an indication of the oxidation and loss of strength of the support members themselves, and (4) nondestructive examination of the support blocks during refueling outages to directly determine the density and strength.

The first three methods mentioned are all currently in use to evaluate degradation of the support structure but none is a direct measure of the actual support block. The last mentioned method is under development with plans to test the approach in the Fort Saint Vrain HTGR at the earliest possible time. The efforts to develop this process and the assembly of the equipment for the in situ tests are the subjects of this document.

\section{NONDESTRUCTIVE EVALUATION}

The ultimate goal of this study is to be able to directly measure or accurately infer the strength of the graphite support members. Thus, an effort was undertaken to develop a technique for testing the graphite blocks supporting the reactor core. The desired approach was to measure the modulus of the graphite and analytically relate the strength to the modulus. Alternately, if necessary, one could measure other properties such as density and density profile and, with a knowledge of the temperature and type of oxidation, correlate the strength with that property. In attempting to develop a suitable technique for evaluating the strength of the support graphite in a HTGR in general and of Fort Saint Vrain in particular, we have examined and developed ultrasonic velocity and backscatter, and eddy current techniques. A brief description of each technique is contained in the following paragraphs. Sonic Velocity Measurements

From a review of available nondestructive techniques, Morgan and Becker (1974) selected ultrasonic velocity measurements as the best method for a direct measurement of strength. This technique transmits an ultrasonic pulse 
through the material of known thickness and determines the velocity of propagation. The relationship of modulus to the sonic velocity was developed nearly four decades ago and is given by the expression (Love, 1944)

$$
v^{2}=\frac{E}{\rho} \frac{(1-\sigma)}{(1+\sigma)(1-2 \sigma)}
$$

where $V=$ ultrasonic wave velocity (longitudinal mode)

$E=$ Young's modulus

$\rho=$ density

$\sigma=$ Poisson's ratio.

Morgan and Becker further described the use of this technique in conjunction with the Griffith Theory (Griffith, 1920) to determine the strength of graphite as given by the expression

$$
S \approx(E / \sigma)^{\gamma} \sim K\left(\frac{\rho}{\sigma}\right)^{\gamma} v^{2 \gamma} \approx K^{\prime} v^{\beta}
$$

where $S$ is breaking stress or strength

$\gamma$ is an unknown constant

$K$ and $K^{\prime}$ are nearly constant

$B$ is equal to or greater than $2 \sigma$.

These equations were tested on several graphite types using right cylinders and found to hold for unoxidized samples and for samples oxidized in $\mathrm{CO}_{2}$ up to several percent weight loss. 0xidation conditions were varied over a wide temperature range to yield a range of results from nearly homogeneous oxidation to surface oxidation (Morgan, 1977; 1979). As a result of these tests, we concluded that the strength could be determined with sufficient confidence for cylindrical posts with as much as 10 percent of the graphite removed by oxidation. However, since both sides of the the support block are not accessible, the direct evaluation of strength by transmission tests was not possible. We, therefore, selected the eddy current and sonic backscattering techniques as the measurement techniques to be used when only single surface access is available. These methods are less direct in that they are a 
measure of the density profile of the samples, rather than a direct measure of the modulus. The strength of the support block can then be calculated from the density profiles by comparing them with profiles from samples in which the strength has been destructively determined.

\section{Eddy Current Measurements}

Eddy current inspection is based upon measurement of conductivity of a material by electromagnetic induction (Figure 1). A sinusoidal constant amplitude current flow through a single test coil causes eddy currents to flow in the test object. These eddy currents produce a secondary field which combines with the primary or excitation field. The combined fields produce a complex signal at the test coil which can be de-convolved to define the conductivity of the material under test. Under test conditions, the interaction of the test coil and material is balanced against a known standard. Variations in the sample under test unbalance the instruments electronic bridge and produce an unbalanced signal which is used to define changes in the conductivity of the test sample. This signal can be described by an amplitude and a phase angle with respect to the test coil exciting-current (Libby, 1979; Am. Soc. Metals, 1976). Since the depth of penetration of the electromagnetic field is

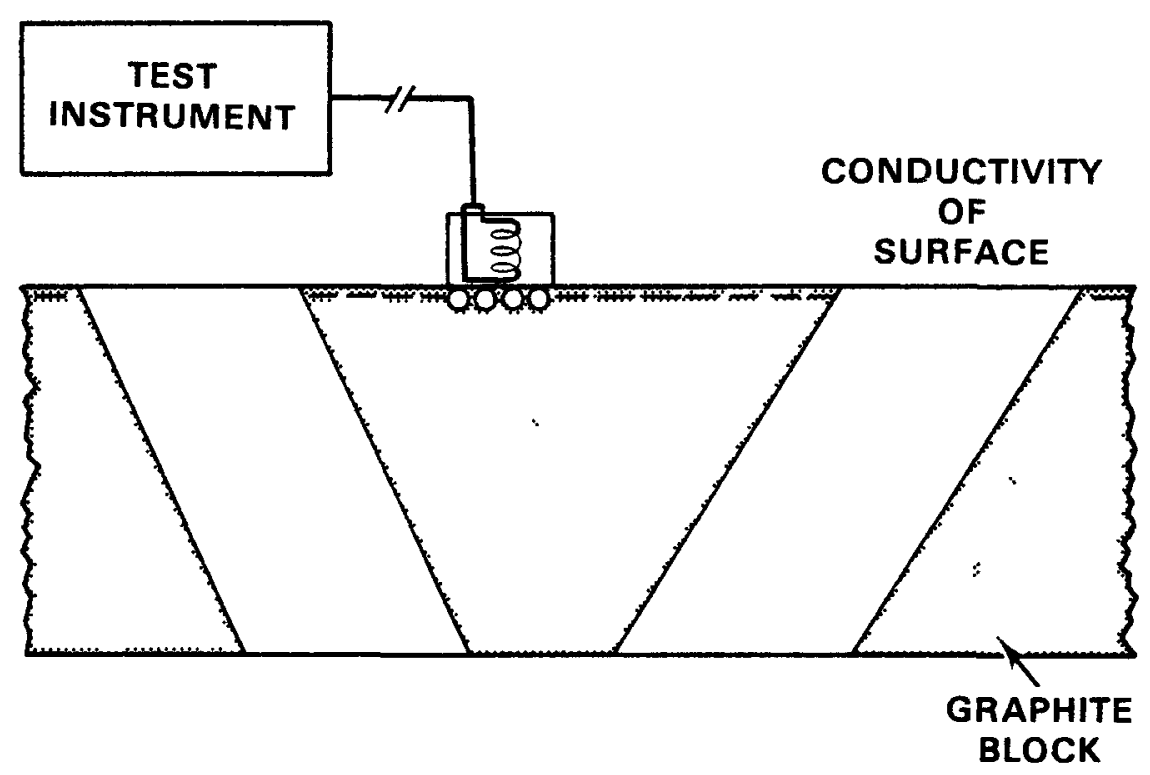

FIGURE 1. Eddy Current Technique 
a function of frequency and permeability of the material, the inspection depth can be selected by choosing an appropriate test frequency.

From the electrical conductivity, one can infer a variety of other properties when the data are compared with that of well characterized standard samples. Other properties which may be determined include magnetic permeability, grain size, composition, hardness, physical dimensions, presence of defects, porosity, density, and other microstructural parameters. Although the eddy current technique has been principally used for metals, it can also be used for evaluation of other electrically conducting materials. Previous studies have been conducted using eddy current methods to examine defects in the structure of graphite billets (0aks, 1971) and graphite fiber reinforced polymers (Owston, 1976).

Because of the wide variety of applications of eddy current techniques, we have examined it as a measure of the density or, more specifically, the near surface density profile of oxidized graphite samples. In this study, we have demonstrated that conductivity of oxidized graphite sample can be measured at the surface of the sample to a depth of about $3 \mathrm{~mm}$. The profile of the oxidation is determined by using multiple frequency examination and correlating the results (both amplitude and phase angle) with the results from well characterized, oxidized plates of graphite. A computer algorithm (ZFIT) has been developed which used the theory developed by Dodd (Dodd, 1975; Deeds, 1979), along with the eddy current data, to calculate the conductivity profile for a thin layer near the surface of the graphite sample. Furthermore, the algorithm, using data from three frequencies (100 KHz, $1 \mathrm{MHz}$, and $4 \mathrm{MHz}), \mathrm{cal}-$ culates the oxidation profile by comparing the conductivity with standard sample conductivity profiles. The energy from each frequency penetrates to a different depth in the graphite, the low frequency achieving the deepest penetration. In order to obtain an accurate correlation of conductivity and oxidation at the higher frequencies, it was necessary to minimize coil resonance caused by stray capacitance in the coil and in the coaxial connecting cables. This has been accomplished and laboratory experiments confirm that the tests $c$ an be performed through the frequency range of interest. Thus, near surface 
oxidation profiles can be determined in graphite samples with sufficient accuracy for monitoring loss of strength in an oxidized HTGR support block. U1trasonic Backscatter

Although the oxidation of the graphite support structure will most likely be limited to the near surface region, recent information (Morgan, 1981) has shown the potential for oxidation in depth. We, therefore, felt it necessary to supplement the eddy current examination with one which could detect oxidation at depths beyond $3 \mathrm{~mm}$ into the graphite block. As only single side access is available, the most promising method for this examination appears to be an ultrasonic backscatter technique. In this system, an ultrasonic transducer is coupled to the graphite sample and sound waves propagating in the media are scattered by grain boundaries, pores, and other defects present. Measurement of the amplitude of the backscattered ultrasound yields information on the microstructure which scatters them. A theoretical description of the backscatter technique for measuring the size of grain boundaries is given by Hecht, et a1. (1981). The ultrasonic backscatter technique being proposed for density profile measurements is shown in Figure 2. A two-transducer configuration (one transmitter, one receiver) is used for the measurement. The transmitting transducer propagates energy at several discrete frequencies (i.e., $500 \mathrm{kHz}, 750 \mathrm{kHz}, 1.5 \mathrm{MHz}, 2.0 \mathrm{MHz}$ ). The receiver transducer, which is responsive to the energies transmitted, is positioned to "intercept" the

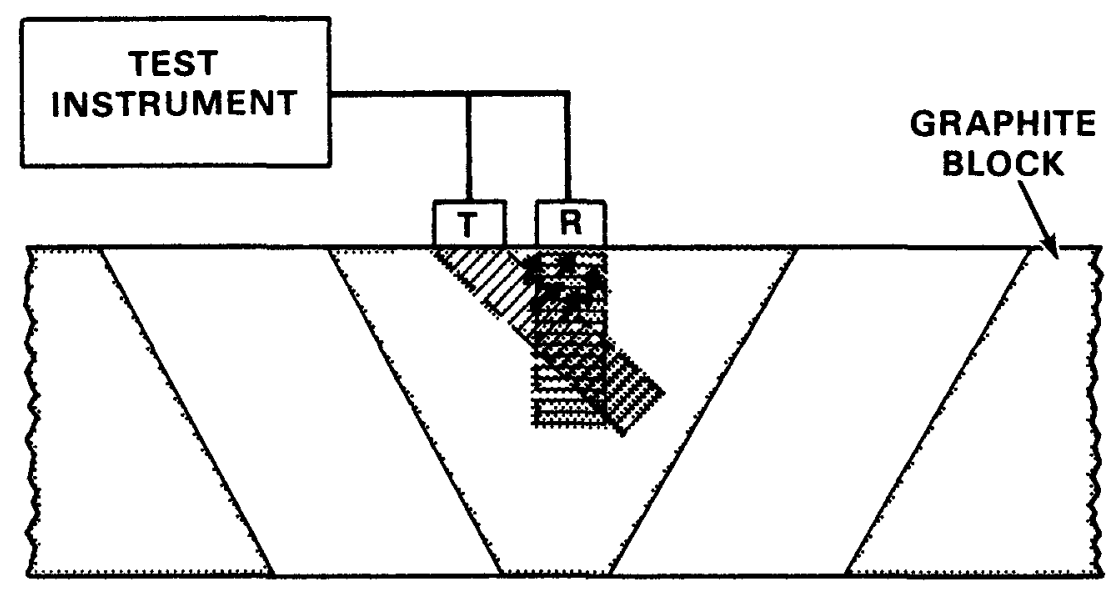

FIGURE 2. UTtrasonic Backscatter Technique (Subsurface Oxidation) 
transmitted beam at a chosen depth. This feature allows one or more specific depths to be investigated. Measurements will be made at several points within the test zone. Temporal averaging techniques will be used to enhance the signal response and spatial averaging will be employed to normalyze responses from local anomolies which are not representative of the average condition of the material. Tests are proceeding to select the appropriate frequencies and to develop the algorithm from which the degree of oxidation will be assessed. Examination of Fort Saint Vrain Support Block

Plans are currently underway to non-destructively examine the core support blocks of the Fort Saint Vrain gas cooled reactor. The purposes of the initial examination are two fold: 1) To demonstrate that a meaningful nondestructive examination can be completed on a support block of a commercial, operating, HTGR during the refueling cycle, and 2) To obtain baseline data on the response of the Fort Saint Vrain reactor support block to eddy current and sonic scattering tests as a future reference for monitoring the oxidation of the structure.

Demonstration of feasibility should be readily accomplished during the first examination, although needed improvements to both the procedure and equipment will undoubtedly become evident. The applicability of the baseline data, however, is not so neatly defined. It would have been desirable to obtain this type of data prior to startup testing of the reactor, and this procedure is recommended for future reactors. The techniques were not available prior to startup of the Fort Saint Vrain reactor, but it would still appear prudent to obtain baseline data at the earliest opportunity. The total oxidation to date is undoubtedly very small and probably insignificant as it relates to loss of strength. Furthermore, any excessive localized oxidation would likely be recognized by comparison with our laboratory test samples. One other uncertainty is the need to extrapolate the data obtained from one refueling region to the entire support block. In spite of these uncertainties, we believe that the initial data will permit us to detect, much more confidently, oxidation and strength loss to the support block during future normal operation or unusual occurrences. 
The support block of the reactor is accessible only through the reactor core. Upon removal of a region of the hexagonal fuel elements, access is achieved to both the removable and permanent reflector blocks. These will be removed to obtain direct access to the support block. As presently envisioned, we would attach a single fixture, containing the eddy current and ultrasound test heads and electronics to the fuel handling machine. This machine will position the NDE instrument package at various locations for testing. Ideally, we would have a sufficient number of conductors to operate the T.V. camera, the eddy current, and the ultrasound probes independently but, due to the difficulty of adding conductors to the fuel handling machine, we have elected to "time share" the existing cables.

The test system planned for the Fort Saint Vrain test is shown in the block diagram (Figure 3.). The ultrasound and eddy current probes, along with their driver/preamp circuitry will be attached to the grapple head of the fuel handling machine. These systems will share three existing coax lines with the T.V. camera through a coax switch arrangement.

The ultrasonic system is a specially designed electronic test instrument using an ultrasonic probe to provide the data needed for the waveform averaging and backscatter analysis. This analysis will provide data on both distributed oxidation and voids in the material.

The eddy current system is a commercially available multiple frequency unit. It will be used to acquire graphite conductivity data from three test frequencies. The three different frequencies provide three sets of data which are a function of the depth of penetration of each of the frequencies. From these data a profile of the conductivity from the surface to a depth of three millimeters $c$ an be computed. From this conductivity information the oxidation profile can be deduced.

The system controller is an HP-85 small computer system, which includes dual floppy disc storage for archiving oxidation data in the field. The system controller will control the test sequence and manage the storage of the oxidation data onto the disc. It will also be used to perform preliminary analysis on the data at Fort Saint Vrain to verify data validity before 


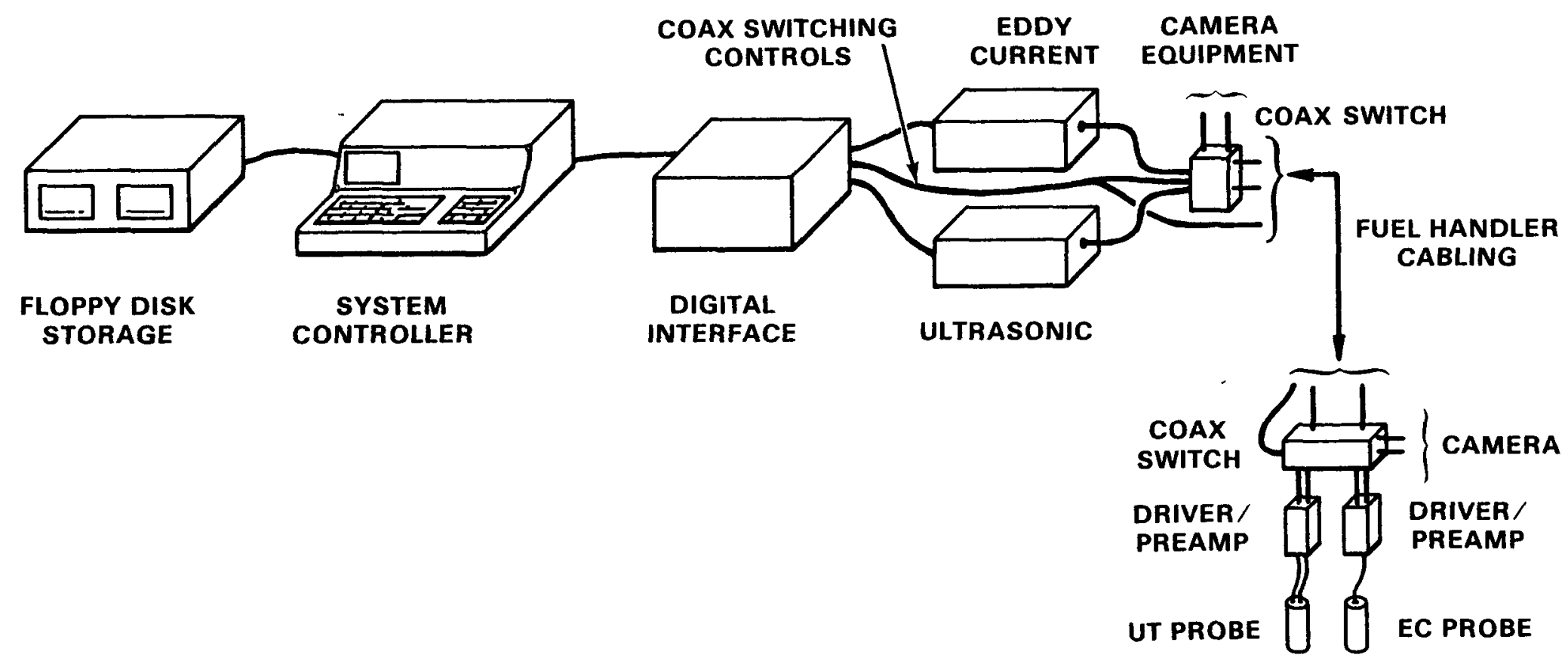

GRAPHITE SUPPORT BLOCKS

FIGURE 3. Fort St. Vrain HTGR Support Block Test System 
bringing it back to the Laboratory for a more detailed analysis. The digital interface transposes data into a form suitable for the system controller.

Preparations are currently underway with the goal of making the first measurements in Fort Saint Vrain during the 1983 refueling outage. As now planned, initial measurements will be made in a single refueling region thus reducing the impact on the refueling process. The resulting data will be carefully analyzed and results interpreted by comparing with laboratory prepared samples. It is assumed that the baseline data obtained will have application to the entire support block and permit accurate evaluation of oxidation occurring as later measurements are made in other refueling regions. The verification of this assumption must await a return to the same refueling region which is expected to occur in 1989.

\section{CONCLUSIONS AND RECOMMENDATIONS}

Non-destructive detection of changes in the strength of graphite support structures in a HTGR appears to be feasible using sonic velocity measurements where access for through transmission is possible. Therefore, future HTGR designs should consider providing such access. Where access is not available, strength changes $c$ an be correlated with oxidation profiles in the support member. These oxidation profiles can be determined non-destructively by a combination of eddy current measurements to detect near surface oxidation and sonic backscattering measurements designed to determine oxidation in depth.

The Fort Saint Vrain reactor provides an operating reactor to test the applicability of the eddy current and sonic backscattering techniques for determination of oxidation in a support block. Furthermore, such tests in Fort Saint Vrain will supply base line data which will be useful in assuring an adequate strength of the support structure for the lifetime of the reactor. Equipment is, therefore, being developed for tests to be conducted during the next major refueling of the reactor. 


\section{REFERENCES}

American Society for Metals. 1976. "Nondestructive Inspection and Quality Control." Metals Handbook (II) 75-92, Metals Park, Ohio.

Deeds, W. E., C. V. Dodd, and G. W. Scott. 1979. "Computer-Aided Design of Multifrequency Eddy-Current Tests for Layered Conductors with Multiple Property Variations." ORNL/TM-6858, Oak Ridge National Laboratory, Oak Ridge, Tennessee.

Dodd, C. V. and W. E. Deeds. 1975. "Calculations of Magnetic Fields from Time-Varying Currents in the Presence of Conductors." ORNL-TM-4958, 0ak Ridge National Laboratory, Oak Ridge, Tennessee.

Griffith, A. A. 1920. "The Phenomena of Rupture and Flow in Solids." Phil. Trans. Royal Soc. (London), A221:163.

Hecht, A., R. Thiel, E. Neumann, and E. Mundry. 1981. "Nondestructive Determination of Grain Size in Austenitic Sheet by UItrasonic Backscattering," Materials Evaluation, (39):934.

Libby, Hugo L. 1979. "Introduction to Electromagnetic Nondestructive Test Methods." Robert E. Krieger Publishing Company, Huntington, New York.

Love, A. E. H. 1944. "A Treatise on the Mathematical Theory of Elasticity," Fourth Edition, Dover Publications, New York.

Morgan, W. C., and F. L. Becker. 1974. "Inservice Monitoring of the Strength of HTGR Core Support Structure." BNWL-B-359, Pacific Northwest Laboratory, Richland, Washington.

Morgan, W. C., and F. L. Becker. 1977. "Feasibility of Monitoring the Strength of HTGR Core Support Graphite - Part I." BNWL-2239, Pacific Northwest Laboratory, Richland, Washington.

Morgan, W. C., and F. L. Becker. 1979. "Feasibility of Monitoring the Strength of HTGR Core Support Graphite - Part II." NUREG/CR-0995 (PNL-3126), Pacific Northwest Laboratory, Richland, Washington.

Morgan, W. C., and M. T. Thomas. 1981. "The Inverse 0xidation Phenomenon." PNL-SA-9689, Pacific Northwest Laboratory, Richland, Washington, (accepted for publication in (ARBON).

Oaks, Arthur E. 1971. "New and Refined Nondestructive Techniques for Graphite Billets and Shapes." AD-736 774, General Electric Company, Philadelphia, Pennsylvania.

Owston, C. N.. 1976. "Eddy Current Methods for the Examination of Carbon Fiber Reinforced Epoxy Resins," Mater. Eval., 34:237. 


\section{ACKNOWLEDGMENT}

The application of the techniques described herein to the graphite support structure has largely been accomplished under sponsorship of the office of Nuc lear Regulatory Research, U.S. Nuclear Regulatory Commission. The construction of the equipment and testing in the Fort Saint Vrain Reactor is sup-

ported by Gas Cooled Reactor Program and Division, U.S. Department of Energy. 


\section{DISTRIBUTION}

No. of

Copies

OFFSITE

A. A. Churm

DOE Patent Division

9800 S. Cass Avenue

Argonne, IL 60439

F. E. Dearing

Department of Energy

Oak Ridge, TN 37830

3 J. E. Fox

Nuclear Research and Applications

Department of Energy

Washington, D.C. 20545

W. L. Vonflue

San Francisco Operations Office

Department of Energy

1333 Broadway

Oakland, CA 94612

27 DOE Technical Information Center

C. Hastings

Army Materials and Mechanics Research Center

Watertown, MA 02172

R. A. Meyer

Aerospace Corporation

P.0. Box 92957

Los Angeles, CA 90009

G. W. Morelli

Airco Speer Carbon-Graphite Corporation

800 Theresia St., Box 433

St. Marys, PA 15857
No. of

Copies

C. A. Sastre

Brookhaven National Laboratory

Upton, NY 11973

Robert Whitesel

Electric Power Research

Institute

3412 Hillview Ave.

P.0. Box 10412

Palo Alto, CA 94303

H. L. Gotschall

Gas Cooled Reactor Associates

3344 N. Torrey Pines Ct.,

STE-300

La Jolla, CA 92037

F. E. Swart

Gas Cooled Reactor Associates

3344 N. Torrey Pines Ct., STE-300

La Jolla, CA 92037

T. D. Gulden

General Atomic Company

P.0. Box 81608

San Diego, CA 92138

A. J. Neylan

General Atomic Company

P.0. Box 81608

San Diego, CA 92138

W. A. Simon

General Atomic Company

P.0. Box 81608

San Diego, CA 92138

R. D. Burnette

General Atomic Company

P.0. Box 81608

San Diego, CA 92138 
No. of

Copies

I. W. Gazda

Great Lakes Carbon Corporation Niagara Falls, NY 14302

M. Stevenson

Los Alamos Scientific Laboratory

P.0. Box 1663

Los Alamos, NM 87544

M. A. Kinna

Department of Navy

Washington, D.C. 20555

2 R. Foulds

Nuc lear Regulatory Commission Washington, D.C. 20555

G. Kuzmyez

Nuc lear Regulatory Commission

Washington, D.C. 20555

P. M. Williams

Nuc lear Regulatory Commission

Washington, D.C. 20555

R. A. Clark

Nuclear Regulatory Commission

Washington, D.C. 20555

S. J. Ball

Oak Ridge National Laboratory

P.0. Box $X$

Oak Ridge, TN 37830

W. P. Eatherly

Oak Ridge National Laboratory

P.0. Box $X$

Oak Ridge, TN 37830

A. P. Malinausk as

Oak Ridge National Laboratory

P.0. BoX $X$

Oak Ridge, TN 37830
No. of

Copies

R. P. Wichner

Oak Ridge National Laboratory

P.0. Box X

Oak Ridge, TN 37830

P. A. Thrower

Department of Materials Science

Pennsylvania State University

University Park, PA 16802

C. P. Murphree

POCO Graphite, Incorporated

P.0. Box 2121

Decatur, TX 76234

J. L. Helm

Proto-Power Management

Corporation

591 Toquonnock Road

Groton, CT 06430

2 L. Brey

Fort St. Vrain Nuclear Generating Station

Public Service of Colorado

406 Coffman

Longmont, CO 80501

J. Reesy

Fort St. Vrain Nuclear Generating Station

Public Service of Colorado

406 Coffman

Longmont, CO 80501

R. R. Paxton

Pure Carbon Company

P.0. Box 386

St. Marys, PA 15857

D. W. Ballard

Sandia Laboratories

Albuquerque, NM 87115 
No. of

Copies

S. Stawrett

Sourthern Research Institute

Birmingham, AL 35205

W. A. Nystrom

Carbon Division

Stackpole Carbon Company

St. Marys, PA 15857

J. C. Bowman

Parma Technical Center

Union Carbide Corporation

Parma, $\mathrm{OH} 44130$

D. B. Fischback

Dept. of Mining

Metallurgy and Ceramic

Engineering

University of Washington

Seattle, WA 98195

C. A. Pratt

Wright Patterson Air Force Base

Dayton, $\mathrm{OH} 45433$
No. of

Copies

ONSITE

DOE Richland Operations Office

H. E. Ransom

United Nuclear Industries, Inc.

W. K. Alexander

35 Pacific Northwest Laboratory

G. L. Tingey (10)

G. J. Posakony (5)

J. A. Prince (5)

W. C. Morgan

R. W. Hill

D. L. Lessor

P. E. Hart

C. A. Hann

A. M. Sutey

W. J. Gray

L. R. Bunnell

Publishing Coordination (2)

Technical Information (5) 